\title{
Effect of Sunlight Exposure and Different Withering Durations on Theanine Levels in Tea (Camellia sinensis)
}

\author{
Janet Chebet Too', ${ }^{1}$ Thomas Kinyanjui ${ }^{1}$, John Kanyiri Wanyoko ${ }^{2}$, Francis Nyamu Wachira ${ }^{3}$ \\ ${ }^{1}$ Department of Chemistry, Egerton University, Egerton, Kenya \\ ${ }^{2}$ KALRO-Tea Research Institute, Kericho, Kenya \\ ${ }^{3}$ Association for Strengthening Agricultural Research in East and Central Africa, Entebbe, Uganda \\ Email: janettietoo@yahoo.com
}

Received 28 May 2015; accepted 20 August 2015; published 24 August 2015

Copyright (C) 2015 by authors and Scientific Research Publishing Inc.

This work is licensed under the Creative Commons Attribution International License (CC BY).

http://creativecommons.org/licenses/by/4.0/

(c) (i) Open Access

\begin{abstract}
Theanine is a non-protein amino acid representing as much as $\mathbf{5 0 \%}$ of the total amino acids in black tea and $1 \%-2 \%$ of dry weight in green tea. It has been shown to be able to reduce high blood pressure, promote relaxation, and inhibit caffeine's side effects among others. This current study explored the effects of sunlight and withering durations on theanine levels in tea shoots. Theanine content from three leaves and a bud, two leaves and a bud and internodes were detected and quantified by using High Performance Liquid chromatography (HPLC). Sunlight exposure experiment was started at dawn (0600 HRS, GMT + 3.00) when the light intensity was low and tea was collected at three-hour interval throughout the day to $(1800 \mathrm{Hrs}$, GMT +3.00$)$ when the light intensity had dropped. At the start of the experiment, the theanine levels were significantly high but as the intensity of sunlight increased during the day there was a significant drop in theanine levels, and as the sun set the theanine levels increased significantly again in all samples. The results also showed that theanine levels were significantly increased after 15 hours of withering. Three leaves and a bud withered for 3 hours had mean theanine levels of $1.41 \%$ and those withered for 15 hours had mean theanine levels of $3.11 \%$. Internodes exhibited higher mean theanine levels than those of leaves. In the light of these results, it's evident that withering for a longer period of time and harvesting of tea when the light intensity is low ensure high amount of theanine in tea.
\end{abstract}

\section{Keywords}

Green Tea, Theanine, Withering Time, Sunlight Exposure, Health Benefits

How to cite this paper: Too, J.C., Kinyanjui, T., Wanyoko, J.K. and Wachira, F.N. (2015) Effect of Sunlight Exposure and Different Withering Durations on Theanine Levels in Tea (Camellia sinensis). Food and Nutrition Sciences, 6, $1014-1021$. 


\section{Introduction}

Tea is one of the most popular and widely consumed beverages in the world because of its refreshing taste, attractive aroma, and potential health benefits [1]-[3]. It is made from the tender leaves of the plant Camellia sinensis (L.). This plant is native to East and South-Eastern Asia [4]. Generally, tea can be broadly classified according to the processing methods as: un-aerated tea (green tea), semi-aerated tea (Oolong tea), fully aerated tea (black tea) or post-aerated tea (pu-erh tea) [5]. A lot of epidemiological and preclinical studies have demonstrated that drinking tea may reduce the risk of cancer and cardiovascular disease [6] [7]. Moreover, other biological functions of tea have also been reported, such as anti-inflammation, anti-allergy, and anti-obesity [6] [8]. These beneficial effects have been attributed to the presence of compounds, such as polyphenols, amino acids, vitamins, carbohydrates, and purine alkaloids [9]. Catechins, which are polyphenols, are known for their antioxidant-related effects [10] [11] and theanine is one of its biosynthetic precursors [12].

Theanine is a non-protein amino acid that was first discovered in tea leaves [13] and has also been found in bay bolete mushroom, Xerocomus badius [14] [15]. It is the main free amino acid in teas representing as much as $50 \%$ of the total amino acids in black tea and $1 \%-2 \%$ of the dry weight of green tea [16] [17]. Besides the four traditional tastes that is sweet, salty, acid, and bitter, theanine is the predominant amino acid in green tea leaves giving tea its characteristic umami or " 5 th taste" [18]-[20]. It not only plays an important role in the characteristic flavour and delicate taste of tea [21], but also shows many biological effects. It is involved in many biological activities such as promoting relaxation, inhibiting caffeine's negative effects, reducing blood pressure, and enhancing anti-tumor activity [22]-[26]. Moreover, it has been reported to have physiological activities including neuroprotection and anti-obesity [27]-[29]. Theanine levels have been determined in the tea shoot but no much work has been reported on different partitions of the shoot to determine where it is mainly concentrated. This study aimed at determining theanine levels in different partitions of the tea shoot with respect of the effect of sunlight and withering on tea shoots.

\section{Materials and Method}

\subsection{Sampling and Processing}

Samples comprising three leaves and a bud were randomly collected (hand plucked) from the respective plot at the Tea Research Institute (Botany/Genetics plots), Kericho (0²2' South, 35 ${ }^{\circ} 21^{\prime}$ East, elevation $2180 \mathrm{~m}$ a.m.s.l). The samples ( $2 \mathrm{~kg}$ ) were put in brown paper bags and taken to the miniature factory in the institute for processing green tea. This was done at an interval of three hours with the last sample being collected after twelve hours. Sampling started early in the morning before sunrise 0 hrs (0600 HRS, GMT + 3.00), 3 hrs (0900 HRS, GMT + 3.00), 6 hrs (1200 HRS, GMT + 3.00), 9 hrs (1500 HRS, GMT + 3.00) and the last sample was collected late in the evening after sunset 12 hrs (1800 HRS, GMT + 3.00). All the samples were split into two, one batch was steamed immediately and the other batch left to wither for different durations. The first collected sample withered for fifteen hours with the last collected sample withering for three hours. The withered samples were then steamed using an electric steamer and the three leaves and a bud were partitioned into seven: bud, first leaf, first leaf internode, second leaf, second leaf internode, third leaf and third leaf internode. They were then microwave dried (GEO103MB, Samsung, Malaysia) in the Institute's miniature factory and the processed tea was finely milled using an electric coffee grinder (AR 40, Moullinex, China) and stored in well labeled aluminium lined sachets.

\subsection{Sample Preparation}

$1.00( \pm 0.01) \mathrm{g}$ of a finely ground sample was weighed into a $200 \mathrm{ml}$ beaker and $100 \mathrm{ml}$ of boiling water was added. The sample was then allowed to brew for $5 \mathrm{~min}$ on a hot plate and the magnetic stirrer put into it. The sample was allowed to cool down, made up to volume and filtered using a $0.45 \mu \mathrm{m}$ membrane before injection.

\subsection{Standard Solution Preparation}

Standard stock solution: $50 \mathrm{mg}$ of pure L-theanine was weighed and put into a $50 \mathrm{ml}$ volumetric flask, dissolved with double distilled water by the aid of sonication and made up to the volume with the double distilled water. Standard working solutions were prepared by serial dilution of the standard stock solution. They were in the 
concentration range of $20-80 \mu \mathrm{g} / \mathrm{ml}$.

\subsection{Chromatographic Determination of Theanine}

Theanine content was determined using High Performance Liquid Chromatography (HPLC). The HPLC used was a Shimadzu LC 20 make fitted with a SIL 20A auto sampler and a SPD-20 UV-Visible detector (set at 210 $\mathrm{nm}$ ) with a class LC10 chromatograph workstation, manufactured in Kyoto, Japan. The column used was RP-18 (phenomenex Aqua $250 \times 4.6$ i.d) and oven was set at $35^{\circ} \mathrm{C}$. The mobile phases used were $100 \%$ HPLC grade acetonitrile and double distilled water. Flow rate was $1 \mathrm{ml} / \mathrm{min}$ and an injection volume of $20 \mu \mathrm{L}$. Each sample was being run for 41 minutes and theanine was eluted between $5^{\text {th }}-6^{\text {th }}$ minute. During the first 22 minutes, the mobile phase used was HPLC grade acetonitrile and the remaining time was used for washing the column with double distilled water. The values were tabulated and a calibration graph was drawn by using concentration of theanine in the working solutions against peak area. A linear calibration line was obtained with slope and intercept value ( $\mathrm{m}$ and $\mathrm{b}$ as in $\mathrm{y}=\mathrm{mx}+\mathrm{b}$ ). The theanine content, $\mathrm{W}_{\text {theanine, }}$, was expressed as a percentage by mass on a dry matter sample basis, as given by the formula:

$$
\mathrm{W}_{\text {theanine }}(\% \mathrm{dw})=\left[\left(\mathrm{A}_{\text {sample }}-\mathrm{B}_{\text {intercept }}\right) \times \mathrm{V}_{\text {sample }} \times \mathrm{DF} \times 100\right] /\left[\mathrm{M}_{\text {std }} \times \mathrm{M}_{\text {sample }} \times 10000 \times \mathrm{W}_{\text {DM sample }}\right]
$$

where:

$\mathrm{A}_{\text {sample }}$ is the peak area obtained for the sample test solution;

$\mathrm{B}_{\text {intercept }}$ is the $\mathrm{y}$ intercept;

$\mathrm{V}_{\text {sample }}$ is the volume of sample injected for HPLC analysis;

$\mathrm{M}_{\mathrm{std}}$ is the slope obtained from the best fit linear calibration;

$\mathrm{M}_{\text {sample }}$ is the mass, in grams, of the sample portion;

DF is the dilution factor used prior to the injection on to an HPLC;

$\mathrm{W}_{\mathrm{DM} \text { sample }}$ is the dry matter content, expressed as a mass fraction in percent, of the test sample.

\section{Results and Discussion}

Theanine levels were determined in various partitions of the tea shoot and in this study three leaves and a bud were sampled for partitioning. TRFK 301/1 cultivar was used in this study and it was adopted from a study done by Kilel et al. [30] who had determined theanine levels in available commercial green clones. This clone contained high levels of theanine $(2.03 \% \mathrm{dw})$. Young two-leaf flushes are typically chosen for manufacturing the finest tea because theanineaccumulates in growing shoots [31]. The tea leaves ( 3 leaves + bud) were partitioned into: bud, first leaf, first leaf internodes, second leaf, second leaf internodes, third leaf and third leaf internodes. The results were as shown in Figure 1.

The buds contained $1.47 \% \mathrm{dw}$ of theanine at the start of the experiment and after three hours the levels decreased to $0.85 \% \mathrm{dw}$. After six hours theanine levels increased to $1.56 \% \mathrm{dw}, 1.67 \% \mathrm{dw}$ after nine hours and decreased to $0.63 \% \mathrm{dw}$ after twelve hours of sunlight exposure. There was a significant difference $(p<0.05)$ in theanine levels at the start and after three and twelve hours but there was no significant difference ( $p>0.05)$ after six and nine hours.

The first leaf contained $2.02 \% \mathrm{dw}$ of theanine at 0 Hours and after three hours the levels decreased to $0.95 \%$. The levels increased to $1.12 \% \mathrm{dw}, 1.22 \% \mathrm{dw}$ and $1.68 \% \mathrm{dw}$ after six, nine and twelve hours respectively. Theanine levels were high at the start and were significantly different $(\mathrm{p}<0.05)$ from the rest of the durations. There was no significant difference $(\mathrm{p}>0.05)$ in theanine levels in the results obtained after three, six and nine hours. There was a significant difference $(\mathrm{p}<0.05)$ in the theanine levels obtained after twelve hours from all the other durations. The first leaf internode contained $3.88 \% \mathrm{dw}$ of theanine at the start and the levels increased to $4.87 \%$ $\mathrm{dw}, 5.20 \% \mathrm{dw}, 5.49 \% \mathrm{dw}$ and $5.78 \% \mathrm{dw}$ after three, six, nine, twelve hours. There was a significant difference $(\mathrm{p}<0.05)$ in theanine levels at the start and during the other durations but there was no significant difference ( $\mathrm{p}>$ 0.05 ) in theanine levels after three, six, nine and twelve hours.

The second leaf contained $0.98 \% \mathrm{dw}$ of theanine at the start and increased to $1.41 \% \mathrm{dw}$ after three hours. Theanine levels decreased to $1.27 \% \mathrm{dw}$ after six hours and increased to $1.46 \% \mathrm{dw}$ and $1.84 \% \mathrm{dw}$ after nine and twelve hours respectively. There was a significant difference $(p<0.05)$ in theanine levels at the start of the study and after three, nine and twelve hours but there was no significant difference in theanine levels at the start and 


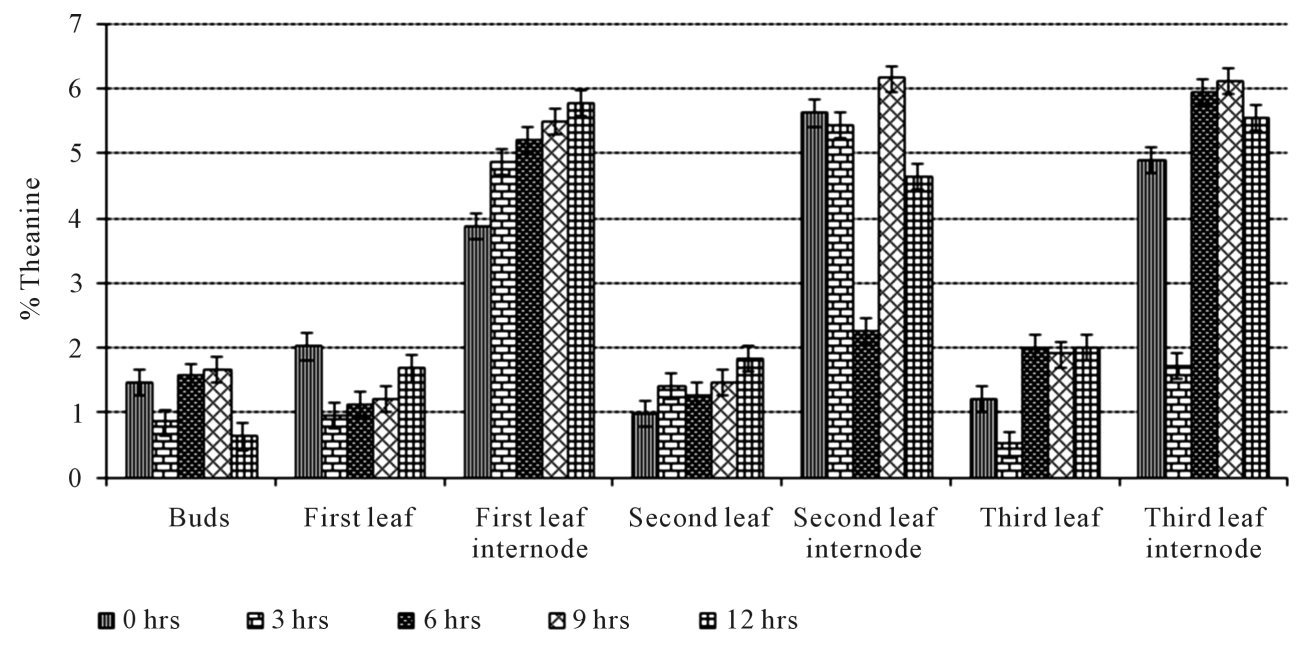

Figure 1. Effect of sunlight exposure on theanine levels in different partitions of tea shoots.

after six hours. The second leaf internode contained 5.62\% dw of theanine at the start and decreased to 5.43\% $\mathrm{dw}$ and $2.25 \% \mathrm{dw}$ after three and six hours respectively. Theanine levels increased to $6.15 \% \mathrm{dw}$ after nine hours and decreased to $4.64 \% \mathrm{dw}$ after twelve hours. There was a significant difference $(\mathrm{p}<0.05)$ in theanine levels at the start and after six, nine and twelve hours but there was no significant difference ( $p>0.05)$ in theanine levels at the start and after three hours.

The third leaf contained $1.20 \% \mathrm{dw}$ of theanine at the start and the levels decreased to $0.51 \% \mathrm{dw}$ after three hours. Theanine levels increased to $2.00 \% \mathrm{dw}$ after six hours, decreased slightly to $1.90 \% \mathrm{dw}$ after nine hours and increased to $2.01 \% \mathrm{dw}$ after twelve hours. There was a significant difference $(\mathrm{p}<0.05)$ in theanine levels at the start and after three, six, nine and twelve hours but there was no significant difference $(p>0.05)$ in the levels obtained after six, nine and twelve hours. The third leaf internode contained $4.90 \% \mathrm{dw}$ of theanine at the start and decreased to $1.71 \% \mathrm{dw}$ after three hours. The levels increased to $5.94 \% \mathrm{dw}, 6.11 \% \mathrm{dw}$ after six and nine hours respectively then decreased to $5.54 \%$ after twelve hours. There was a significant difference $(p<0.05)$ in theanine levels at the start and after all the durations in the study but there was no significant difference ( $>$ 0.05 ) after six and nine hours.

Theanine level has been reported by Kyle et al. [32] to be affected by sunlight exposure. In this study, theanine levels decreased after being exposed to sunlight and this was after 3 hours. This was the only duration where there was maximum sunlight and theanine levels decreased in most of the partitions. The internodes were shown to contain high levels of theanine compared to the leaves. There was no linear pattern to show where theanine can be found to be optimum with respect to the different durations. With the recommended plucking standards of 2 leaves and a bud, theanine levels ranged between $2.23 \%-2.98 \% \mathrm{dw}$ while for 3 leaves and a bud the range was $2.25 \%-3.43 \% \mathrm{dw}$ (Table 1 ). Three leaves and a bud were shown to contain higher theanine levels than two leaves and a bud. Reference [33] conducted a study to determine concentrations of theanine in fresh tea leaves and found out that there was no linear pattern of increasing or decreasing concentrations with respect to age of the leaf and this concurs with the results obtained in this study.

There is little or no documented work done on the internodes as a separate partition. Reference [34] [35] and [36] conducted studies on theanine levels of fresh tea leaves and concluded that theanine levels decrease with age of the leaf and this was not so in this study. The third leaf theanine levels were higher than that of the second leaf and therefore more study has to be done with more leaves.

Theanine levels were also determined in the different partitions of the tea shoot as was done in the above study but now considering the effect of withering time varying from three to fifteen hours and the results were as shown in Figure 2. This was meant to determine if theanine levels increase or decrease upon withering in green tea. The buds contained $0.73 \% \mathrm{dw}$ of theanine after three hours and increased to $1.41 \% \mathrm{dw}$ after six hours. Theanine levels decreased to $0.66 \% \mathrm{dw}$ after nine hours, increased to $1.52 \% \mathrm{dw}$ after twelve hours then decreased slightly to $1.49 \% \mathrm{dw}$ after fifteen hours. There was no significant difference ( $p>0.05$ ) in theanine levels after three and nine hours but were significantly different $(p<0.05)$ from the levels obtained after six, twelve 


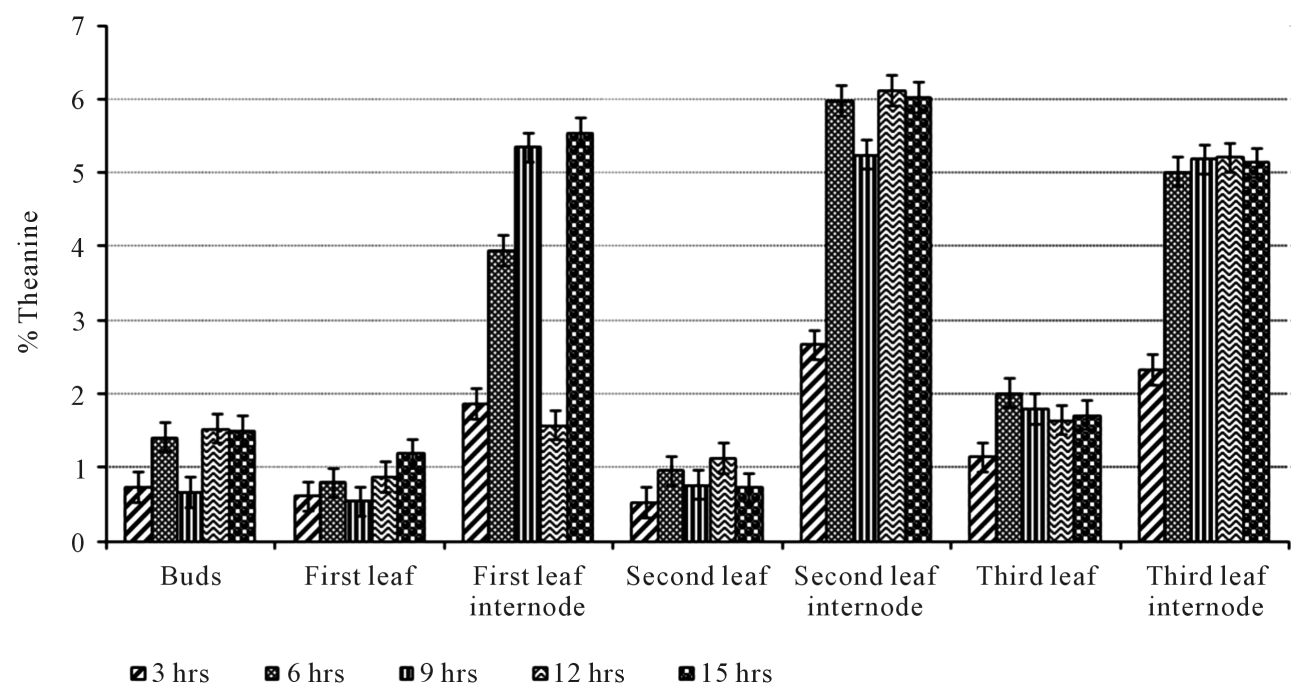

Figure 2. Effect of withering duration in theanine levels in different partitions of the tea shoot.

Table 1. Table showing theanine levels in shoots at exposed to direct sunlight at different time intervals.

\begin{tabular}{cccccc}
\hline & \multicolumn{3}{c}{ Time Intervals } \\
Sunlight Exposure & 0 Hrs & 3 Hrs & 6 Hrs & 9 Hrs & 12 Hrs \\
\cline { 2 - 6 } & 2.87 & 2.25 & 2.76 & 3.43 & 3.16 \\
3L + B & 2.76 & 2.98 & 2.23 & 2.34 & 2.53 \\
\hline
\end{tabular}

$3 \mathrm{~L}+\mathrm{B}=$ Three leaves and a bud, $2 \mathrm{~L}+\mathrm{B}=$ Two leaves and a bud. Figures are in percentage dry weight $(\mathrm{DW})$. Hrs = Hours.

and fifteen hours. There was also no significant difference $(p>0.05)$ in theanine levels after six, twelve and fifteen hours of withering. The first leaf contained $0.61 \% \mathrm{dw}$ of theanine after three hours and increased to $0.79 \%$ $\mathrm{dw}$ after six hours. Theanine levels decreased to $0.54 \% \mathrm{dw}$ after nine hours and increased to $0.87 \% \mathrm{dw}, 1.18 \%$ $\mathrm{dw}$ after twelve and fifteen hours respectively. There was no significant difference $(\mathrm{p}>0.05)$ in theanine levels obtained after three, six, nine and twelve hours. There was also no significant difference $(p>0.05)$ in theanine levels after six, twelve and fifteen hours. There was a significant difference $(\mathrm{p}<0.05)$ in theanine levels obtained after three and nine hours of withering with the levels after fifteen hours. Thefirst leaf internode contained $1.86 \% \mathrm{dw}$ of theanine after three hours.

Theanine levels increased to 3.94\% dw, 5.34\% dw after six and nine hours respectively. The levels then decreased to $1.57 \% \mathrm{dw}$ after twelve hours and increased to $5.54 \% \mathrm{dw}$ after fifteen hours. There was no significant difference $(p>0.05)$ in theanine levels obtained after three and twelve hours of withering and also after nine and fifteen hours of withering. There was a significant difference $(p<0.05)$ in theanine levels obtained after six hours from the other durations.

The second leaf contained $0.52 \% \mathrm{dw}$ of theanine after three hours and the levels increased to $0.95 \% \mathrm{dw}$ after six hours. Theanine levels decreased to $0.76 \% \mathrm{dw}$ after nine hours, increased to $1.12 \% \mathrm{dw}$ after twelve hours and decreased to $0.72 \% \mathrm{dw}$ after fifteen hours. There was no significant difference $(\mathrm{p}>0.05)$ in theanine levels obtained after three, nine and fifteen hours but a significant difference $(p<0.05)$ in the levels obtained after three hours with levels after six and twelve hours. There was also no significant difference $(p>0.05)$ in theanine levels obtained after six, nine, twelve and fifteen hours of withering. The second leaf internode contained $2.66 \%$ $\mathrm{dw}$ of theanine after three hours and increased to $5.97 \%$ after six hours. The levels decreased to $5.24 \% \mathrm{dw}$ after nine hours, increased to $6.11 \% \mathrm{dw}$ after twelve hours and slightly decreased to $6.02 \% \mathrm{dw}$ after fifteen hours. There was a significant difference $(\mathrm{p}<0.05)$ in theanine levels obtained after three and nine hours from the other durations but no significant difference $(p>0.05)$ in the levels obtained after six, twelve and fifteen hours of withering.

The third leaf contained $1.14 \% \mathrm{dw}$ of theanine after three hours and increased to $2.01 \% \mathrm{dw}$ after six hours. 
Table 2. Table showing theanine levels in shoots at different withering time intervals.

\begin{tabular}{cccccc}
\hline \multirow{2}{*}{ Withering } & \multicolumn{5}{c}{ Time Intervals } \\
\cline { 2 - 6 } & 3 Hrs & 6 Hrs & 9 Hrs & 12 Hrs & 15 Hrs \\
\hline $3 \mathrm{~L}+\mathrm{B}$ & 1.41 & 2.87 & 2.79 & 2.58 & 3.11 \\
$2 \mathrm{~L}+\mathrm{B}$ & 1.25 & 2.51 & 2.39 & 2.14 & 2.78 \\
\hline
\end{tabular}

$3 \mathrm{~L}+\mathrm{B}=$ Three leaves and a bud, $2 \mathrm{~L}+\mathrm{B}=$ Two leaves and a bud. Figures are in percentage dry weight $(\mathrm{DW})$. Hrs $=$ Hours.

The levels decreased to $1.79 \% \mathrm{dw}, 1.64 \% \mathrm{dw}$ after nine and twelve hours respectively. After fifteen hours, the levels increased to $1.71 \% \mathrm{dw}$. There was no significant difference $(\mathrm{p}>0.05)$ in theanine levels obtained after six, nine, fifteen hours and also after nine, twelve, fifteen hours of withering. The third leaf internode contained $2.32 \%$ $\mathrm{dw}$ of theanine after three hours. The levels increased to $5.01 \% \mathrm{dw}, 5.18 \% \mathrm{dw}$, and 5.20\% dw after six, nine and twelve hours respectively. The levels decreased to $5.13 \%$ after fifteen hours. There was no significant difference $(p>0.05)$ in theanine levels after six, nine, twelve and fifteen hours of withering.

Theanine levels varied in all the partitions in this study except in the third leaf internode. The internodes were shown to contain high theanine levels compared to the other partitions and especially the second leaf internode. The first two leaves contained the lowest. Two leaves and a bud are plucked to obtain quality tea though three leaves and bud can be plucked but in small amounts. In Table 2, theanine levels have been shown to increase with age of the leaf; high levels in 3 leaves and a bud than 2 leaves and a bud. Withering duration of 3 hrs resulted in a decrease in theanine levels from $3.16 \% \mathrm{dw}$ to $1.41 \% \mathrm{dw}$ of the fresh tea leaves. 6 hrs of withering also resulted in a decrease in theanine levels while there was a slight increase after 9 hrs of withering from $2.76 \%$ $\mathrm{dw}$ to $2.79 \% \mathrm{dw}$. After $12 \mathrm{hrs}$ and 15 hrs of withering, theanine levels increased with the highest level shown after 15 hrs increasing from $2.87 \%$ dw to $3.11 \%$ dw. Reference [37] determined the effect of different withering timings on theanine levels and found out that the levels will increase up to 23 hrs then begin to decrease afterwards. This is in agreement with this study even though withering was only for 15 hrs and the withering duration when theanine levels will decline was not established.

\section{Conclusion}

Theanine levels were shown to be affected by different light intensities and to produce tea with high levels of this amino acid, tea leaves should be plucked when there is minimal sunlight. This is especially very early in the morning before sunrise or late in the evening after sunset. Green tea is not left to wither when processing but in this study it was shown that withering resulted in an increase in theanine. Also, theanine was shown to increase with age of the leaf; third leaf contained high levels than the first and second leaf. More research needs to be done especially to determine the withering duration when optimum theanine can be obtained.

\section{Acknowledgements}

The authors acknowledge the Centre Director, Tea Research Institute, for granting us the permission to publish this work and for funding this project through the tea industry stakeholders.

\section{References}

[1] Alan, C.A., Jaganath, I.B. and Clifford, M.N. (2009) Dietary Phenolics: Chemistry, Bioavailability and Effects on Health. Natural Product Reports, 26, 1001-1043. http://dx.doi.org/10.1039/b802662a

[2] Dufresne, C.J. and Farnworth, E.R. (2001) A Review of Latest Research Findings on the Health Promotion Properties of Tea. The Journal of Nutritional Biochemistry, 12, 404-421. http://dx.doi.org/10.1016/S0955-2863(01)00155-3

[3] Kuo, K.L., Weng, M.S., Chiang, C.T., Tsai, Y.J., Lin-Shiau, S.Y. and Lin, J.K. (2005) Comparative Studies on the Hypolipidemic and Growth Suppressive Effects of Oolong, Black, Pu-Erh, and Green Tea Leaves in Rats. Journal of Agricultural and Food Chemistry, 53, 480-489. http://dx.doi.org/10.1021/jf049375k

[4] Cheng, I.F. and Breen, K. (2000) On the Ability of Four Flavonoids, Baicilein, Luteolin, Naringenin, and Quercetin, to Suppress the Fenton Reaction of the Iron-ATP Complex. Biometals, 13, 77-83. http://dx.doi.org/10.1023/A:1009229429250

[5] Zhao, J.W., Chen, Q.S. and Huang, X.Y. (2006) Qualitative Identification of Tea Categories by near Infrared Spec- 
troscopy and Support Vector Machine. Journal of Pharmaceutical and Biomedical Analysis, 41, 1198-1204. http://dx.doi.org/10.1016/j.jpba.2006.02.053

[6] Khan, N. and Mukhtar, H. (2007) Tea Polyphenols for Health Promotion. Life Science, 81, 519-533. http://dx.doi.org/10.1016/j.lfs.2007.06.011

[7] Yang, C.S., Maliakal, P. and Meng, X.F. (2002) Inhibition of Carcinogenesis by Tea. Annual Review of Pharmacology and Toxicology, 42, 25-54. http://dx.doi.org/10.1146/annurev.pharmtox.42.082101.154309

[8] Fujimura, Y., Tachibana, H. and Yamada, K. (2004) Lipid Raft-Associated Catechin Suppresses the FceRI Expression by Inhibiting Phosphorylation of the Extracellular Signal-Regulated Kinase1/2. FEBS Letters, 556, 204-210. http://dx.doi.org/10.1016/S0014-5793(03)01432-7

[9] Bolling, B.W., Chen, C.Y. and Blumberg, J.B. (2009) Tea and Health: Preventive and Therapeutic Usefulness in the Elderly. Current Opinion in Clinical Nutrition \& Metabolic Care, 12, 42-48. http://dx.doi.org/10.1097/MCO.0b013e32831b9c48

[10] Gradisar, H., Pristovsek, P., Plaper, A. and Jerala, R. (2007) Green Tea Catechins Inhibit Bacterial DNA Gyrase by Interaction with Its ATP Binding Site. Journal of Medicinal Chemistry, 50, 264-271. http://dx.doi.org/10.1021/jm060817o

[11] Morley, N., Clifford, T., Salter, L., Campbell, S., Gould, D. and Curnow, A. (2005) The Green Tea Polyphenol (-)-Epigallocatechingallate and Green Tea Can Protect Human Cellular DNA from Ultraviolet and Visible RadiationInduced Damage. Photodermatology, Photoimmunology and Photomedicine, 21, 15-22. http://dx.doi.org/10.1111/j.1600-0781.2005.00119.x

[12] Kito, M., Kokura, H., Izaki, J. and Sasaoka, K. (1968) Theanine, a Precursor of the Phloroglucinol Nucleus of Catechins in Tea Plants. Phytochemistry, 7, 599-603. http://dx.doi.org/10.1016/S0031-9422(00)88234-5

[13] Sakato, Y. (1949) The Chemical Constituents of Tea: A New Amide Theanine. Journal of Agricultural and Food Chemistry, 23, 262-267.

[14] Syu, K.Y., Lin, C.L., Huang, H.C. and Lin, J.K. (2008) Determination of Theanine, GABA, and Other Amino Acids in Green, Oolong, Black, and Pu-Erh Teas with Dabsylation, and High Performance Liquid Chromatography. Journal of Agricultural and Food Chemistry, 56, 7637-7643. http://dx.doi.org/10.1021/jf801795m

[15] Deng, W.W., Ogita, S. and Ashihara, H. (2010) Distribution and Biosynthesis of Theanine in Theaceae Plants. Plant Physiology and Biochemistry, 47, 70-72.

[16] Hara, Y., Luo, S.J., Wikramasinghe, R.L. and Yamanishi, T. (1995) Special Issue on Tea. Food Reviews International, 11, 371-545.

[17] Palva, S. and Palva, J.M. (2007) New Vistas for $\alpha$-Frequency Band Oscillations. Trends in Neurosciences, 30, $150-158$. http://dx.doi.org/10.1016/j.tins.2007.02.001

[18] Kaneko, S., Kumazawa, K. and Masuda, H. (2006) Molecular and Sensory Studies on the Umami Taste of Japanese Green Tea. Journal of Agricultural and Food Chemistry, 54, 2688-2694. http://dx.doi.org/10.1021/jf0525232

[19] Le Gall, G., Colquhoun, I.J. and Defernez, M. (2004) Metabolite Profiling Using Proton NMR Spectroscopy for Quality Assessment of Green Tea, Camellia sinensis (L.). Journal of Agricultural and Food Chemistry, 52, 692-700. http://dx.doi.org/10.1021/jf034828r

[20] Thippeswamy, R., Mallikarjun, K.G., Gouda, M., Rao, D.H., Martin, A. and Gowda, L.R. (2006) Determination of Theanine in Commercial Tea by Liquid Chromatography with Fluorescence and Diode Array Ultraviolet Detection. Journal of Agricultural and Food Chemistry, 54, 7014-7019. http://dx.doi.org/10.1021/jf061715+

[21] Lee, J.E., Lee, B.J., Chung, J.O., Hwang, J.A., Lee, S.J. and Lee, C.H. (2010) Geographical and Climatic Dependencies of Green Tea (Camellia sinensis) Metabolites: A ${ }^{1} \mathrm{H}$ NMR-Based Metabolomics Study. Journal of Agricultural and Food Chemistry, 58, 10582-10589. http://dx.doi.org/10.1021/jf102415m

[22] Kamath, A.B., Wang, L., Das, H., Li, L., Reinhold, V.N. and Bukowski, J.F. (2003) Antigens in Tea-Beverage Prime Human $\mathrm{V} \gamma 2 \mathrm{~V} \delta 2 \mathrm{~T}$ Cells in Vitro and in Vivo for Memory and Nonmemory Antibacterial Cytokine Responses. Proceedings of the National Academy of Science of the United States of America, 100, 6009-6014. http://dx.doi.org/10.1073/pnas.1035603100

[23] Kimura, K., Ozeki, M., Juneja, L.R. and Ohira, H. (2007) L-Theanine Reduces Psychological and Physiological Stress Responses. Biological Psychology, 74, 39-45. http://dx.doi.org/10.1016/j.biopsycho.2006.06.006

[24] Sugiyama, T. and Sadzuka, Y. (2003) Theanine and Glutamate Transporter Inhibitors Enhance the Antitumor Efficacy of Chemotherapeutic Agents. Biochimica et Biophysica Acta, 5, 47-59. http://dx.doi.org/10.1016/s0304-419x(03)00031-3

[25] Yamada, T. and Terashima, T. (2009) Theanine, Gamma-Glutamylethylamide, a Unique Amino Acid in Tea Leaves, Modulates Neurotransmitter Concentrations in the Brain Striatum Interstitium in Conscious Rats. Amino Acids, 36, 2127. http://dx.doi.org/10.1007/s00726-007-0020-7 
[26] Zhang, L., Zhang, Z.Z., Lu, Y.N., Zhang, J.S. and Preedy, V.R. (2013) L-Theanine from Green Tea: Transport and Effects on Health. In: Preedy, V.R., Ed., Tea in Health and Disease Prevention, Chap. 35, Academic Press, Waltham, 425-435. http://dx.doi.org/10.1016/B978-0-12-384937-3.00035-5

[27] Cho, H.S., Kim, S., Lee, S.Y., Park, J.A., Kim, S.J. and Chun, H.S. (2008) Protective Effect of the Green Tea Component, L-Theanine on Environmental Toxins-Induced Neuronal Cell Death. Neuro Toxicology, 26, 656-662. http://dx.doi.org/10.1016/j.neuro.2008.03.004

[28] Egashira, N., Hayakawa, K., Mishima, K., Kimura, H., Iwasaki, K. and Fujiwara, M. (2004) Neuroprotective Effect of $\gamma$-Glutamylethylamide (Theanine) on Cerebral Infraction in Mice. Neuroscience Letters, 36, 58-61. http://dx.doi.org/10.1016/j.neulet.2004.03.046

[29] Zheng, G., Bamba, K., Okubo, T., Juneja, L.R. and Sayama, I.K. (2005) Effect of Theanine, $\gamma$-Glutamylethylamide, on Bodyweight and Fat Accumulation in Mice. Animal Science Journal, 76, 153-157. http://dx.doi.org/10.1111/j.1740-0929.2005.00251.x

[30] Kilel, E.C., Faraj, A.K., Wanyoko, J.K., Wachira, F.N. and Mwingirwa, V. (2013) Green Tea from Purple Leaf Coloured Tea Clones in Kenya-Their Quality Characteristics. Journal of Food Chemistry, 141, 769-775. http://dx.doi.org/10.1016/j.foodchem.2013.03.051

[31] Chu, D.C., Kobayashi, K., Juneja, L.R. and Yamamoto, T. (1997) Theanine-Its Synthesis, Isolation and Physiological Activity. In: Yamamoto, T., Ed., Chemistry and Applications of Green Tea, CRC Press, Boca Raton, 129-135.

[32] Kyle, J.A.M., Morrice, P.C., McNeill, G. and Duthie, G.G. (2007) Effects of Infusion Time and Addition of Milk on Content and Absorption of Polyphenols in Black Tea. Journal of Agricultural and Food Chemistry, 55, 4889-4894. http://dx.doi.org/10.1021/jf070351y

[33] Chen, C.N., Liang, C.M., Lai, J.R., Tsai, Y.J., Tsay, J.S. and Lin, J.K. (2003) Capillary Electrophoretic Determination of Theanine, Caffeine, and Catechins in Fresh Tea Leaves and Oolong Tea and Their Effects on Rat Neurosphere Adhesion and Migration. Journal of Agricultural and Food Chemistry, 51, 7495-7503. http://dx.doi.org/10.1021/jf034634b

[34] Baptista, J., Lima, E., Paiva, L., Andrade, L.A. and Alves, M.G. (2012) Comparison of Azorean Tea Theanine to Teas from Other Origins by HPLC/DAD/FD. Effect of Fermentation, Drying Temperature, Drying Time and Shoot Maturity. Journal of Food Chemistry, 132, 2181-2187. http://dx.doi.org/10.1016/j.foodchem.2011.12.050

[35] Chen, Y.L., Jiang, Y.M., Duan, J., Shi, J., Xue, S. and Kakuda, Y. (2010) Variation in Catechin Contents in Relation to Quality of "Huang Zhi Xiang” Oolong Tea (Camellia sinensis) at Various Growing Altitudes and Seasons. Food Chemistry, 119, 648-652. http://dx.doi.org/10.1016/j.foodchem.2009.07.014

[36] Song, R., Kelman, D., Johns, K.L. and Wright, A.D. (2012) Correlation between Leaf Age, Shade Levels and Characteristic Beneficial Natural Constituents of Tea (Camellia sinensis) Grown in Hawaii. Journal of Food Chemistry, 133, 707-714. http://dx.doi.org/10.1016/j.foodchem.2012.01.078

[37] Jabeen, S., Alam, S., Saleem, M., Ahmad, W., Bibi, R., Hamid, F.S. and Shah, H.U. (2015) Withering Timings Affect the Total Free Amino Acids and Mineral Contents of Tea Leaves during Black Tea Manufacturing. Arabian Journal of Chemistry, 30, 1-7. http://dx.doi.org/10.1016/j.arabjc.2015.03.011 